\title{
Effects of Biochar Amendment on Tomato Bacterial Wilt Resistance and Soil Microbial Amount and Activity
}

\author{
Yang Lu, ${ }^{1}$ Shuang Rao, ${ }^{1}$ Fei Huang, ${ }^{1}$ Yixia Cai, ${ }^{1}$ Guoping Wang, ${ }^{2}$ and Kunzheng Cai ${ }^{1}$ \\ ${ }^{1}$ Key Laboratory of Tropical Agro-Environment, Ministry of Agriculture, South China Agricultural University, \\ Guangzhou 510642, China \\ ${ }^{2}$ College of Horticulture, South China Agricultural University, Guangzhou 510642, China
}

Correspondence should be addressed to Kunzheng Cai; kzcai@scau.edu.cn

Received 11 April 2016; Accepted 3 August 2016

Academic Editor: Allen Barker

Copyright (C) 2016 Yang Lu et al. This is an open access article distributed under the Creative Commons Attribution License, which permits unrestricted use, distribution, and reproduction in any medium, provided the original work is properly cited.

\begin{abstract}
Bacterial wilt is a serious soilborne disease of Solanaceae crops which is caused by Ralstonia solanacearum. The important role of biochar in enhancing disease resistance in plants has been verified; however, the underlying mechanism remains not fully understood. In this study, two different biochars, made from peanut shell $(\mathrm{BC} 1)$ and wheat straw (BC2), were added to Ralstonia solanacearum-infected soil to explore the interrelation among biochar, tomato bacterial wilt, and soil microbial properties. The results showed that both $\mathrm{BC} 1$ and $\mathrm{BC} 2$ treatments significantly reduced the disease index of bacterial wilt by $28.6 \%$ and $65.7 \%$, respectively. The populations of $R$. solanacearum in soil were also significantly decreased by biochar application. Ralstonia solanacearum infection significantly reduced the densities of soil bacteria and actinomycetes and increased the ratio of soil fungi/bacteria in the soil. By contrast, $\mathrm{BC} 1$ and $\mathrm{BC} 2$ addition to pathogen-infected soil significantly increased the densities of soil bacteria and actinomycetes but decreased the density of fungi and the ratios of soil fungi/bacteria and fungi/actinomycetes. Biochar treatments also increased soil neutral phosphatase and urease activity. Furthermore, higher metabolic capabilities of microorganisms by biochar application were found at 96 and $144 \mathrm{~h}$ in Biolog EcoPlates. These results suggest that both peanut and wheat biochar amendments were effective in inhibiting tomato bacterial wilt caused by $R$. solanacearum. The results suggest a relationship between the disease resistance of the plants and the changes in soil microbial population densities and activity.
\end{abstract}

\section{Introduction}

Bacterial wilt is a serious soilborne disease caused by Ralstonia solanacearum [1]. This disease is difficult to control because the pathogen can survive within a large temperature range $\left(10^{\circ} \mathrm{C}\right.$ to $\left.41^{\circ} \mathrm{C}\right)$ and in diverse environments [2]. $R$. solanacearum can induce persistent latent infection in nursery plants even at low populations in soil or irrigation water [3]. Traditional control methods, including host resistance, crop rotation, and chemical methods, may be limited or elicit negative effects on food safety and environment [4]. Therefore, effective and eco-friendly approaches should be developed to reduce this disease.

Biochar, a product of the thermal degradation of organic materials in the absence of air (pyrolysis), is distinguished from charcoal in terms of usage. In particular, as a soil amendment, biochar can exhibit long-term carbon sequestration potential and reduce greenhouse gas emission and in soil [5]. Biochar can also improve soil tilth [6] and increase crop productivity and competitive ability $[7,8]$. Biochar application can also enhance crop response to disease [9], and this enhancement can be attributed to an increase in soil $\mathrm{pH}$ [10], nutrient retention [6, 11], cation exchange capacity in soil [11], transformations and turnover of $P$ and $S$ [12], and neutralization of phytotoxic compounds in soil [13].

It is reported that biochar can increase plant resistance to disease. For instance, biochar can reduce fungal foliar diseases caused by Botrytis cinerea and Oidiopsis sicula in tomato (Solanum lycopersicum L.) and pepper (Capsicum annuum L.) [14]. Harel et al. suggested that strawberry defense responses mediated by biochars are functionally similar to induced systemic resistance [15]. Moreover, biochar can reduce 
TABLE 1: Basic properties of biochars used in the experiment.

\begin{tabular}{lccccccccc}
\hline Type & Feedstock & Temperature $\left({ }^{\circ} \mathrm{C}\right)$ & $\mathrm{pH}$ & $\mathrm{C}^{\mathrm{a}}(\%)$ & $\mathrm{N}^{\mathrm{a}}(\%)$ & Available P $\left(\mathrm{mg} \mathrm{kg}^{-1}\right)$ & Available K $\left(\mathrm{mg} \mathrm{kg}^{-1}\right)$ & $\mathrm{Ash}^{\mathrm{b}}(\%)$ & $\left.\mathrm{C} / \mathrm{N} \mathrm{ratio}^{2} \%\right)$ \\
\hline $\mathrm{BC} 1$ & Peanut shell & $500 \times 2 \mathrm{~h}$ & 9.89 & 17.41 & 0.60 & 611.3 & 3872 & 70.70 \\
$\mathrm{BC} 2$ & Wheat straw & $500 \times 2 \mathrm{~h}$ & 10.02 & 47.38 & 0.98 & 325.0 & 3820 & 47.60 & 48.35 \\
\hline
\end{tabular}

${ }^{a}$ Molar ratios, analyzed with an elemental analysis apparatus, vario TOC cube, Elementar Analysensysteme GmbH, Germany.

${ }^{\mathrm{b}}$ Mass $\% \mathrm{w} / \mathrm{w}$ analyzed by dry combustion in a muffle furnace at $600^{\circ} \mathrm{C}$ for $2 \mathrm{~h}$.

soilborne diseases caused by bacteria and fungi [16]. Nerome et al. found that bacterial wilt ( $R$. solanacearum) in tomato was reduced by adding biochar derived from municipal biowaste [17]. Suppressions of plant diseases by biochar were attributed to several mechanisms [18-20], including the following. The chemical components of biochar may provide direct inhibition of pathogens and the porous structure of biochar may provide microbial habitats which is good for bacterial abundance. Biochar can also promote plant growth by providing nutrients and improving nutrient solubilization and uptake. To some extent, biochar sorption may change the mobility and activity of pathogens or modify signaling between pathogens and plants [19].

Densities, activity, and diversity of soil microorganisms can be important indicators to evaluate soil health status and soil quality $[21,22]$. Pathogen infection may change soil microbial properties; thus, soil can be converted from a highly fertile bacterial type to poorly fertile fungal type $[23,24]$. Biochar amendments to soils may alter soil function and fertility in various ways, including through induced changes in the microbial community. Kelly et al. found a significant decline in the fungi/bacteria ratio in the Colorado soil with switchgrass biochar [25]. Considering that biochar is implicated in soilborne disease reduction, we hypothesized that disease resistance mediated by biochar may be related to changes in microbial properties. This study aimed to investigate the interrelation among biochar, bacterial wilt resistance, and soil microbial components and activity.

\section{Materials and Methods}

2.1. Plant Materials and Soil Conditions. Tomato cv. Taiwan Red cherry (tomato genotype; produced by Kefeng Seed Co., Ltd., Changchun, Jilin, China), which is susceptible to $R$. solanacearum, was used in this experiment. Tomato seeds were stored in a fridge at $4^{\circ} \mathrm{C}$ and steeped in water at room temperature for $2 \mathrm{~h}$ before use. The seeds were surfacesterilized in water at $50^{\circ} \mathrm{C}$ for $15 \mathrm{~min}$ and then germinated on moist filter paper in Petri dishes. After $2 \mathrm{~d}$, the seeds were sown in nursery soil (tomato farm soil disinfected at $150^{\circ} \mathrm{C}$ for $4 \mathrm{~h}$ ) in a growth chamber with the following conditions: $30^{\circ} \mathrm{C} / 25^{\circ} \mathrm{C}$ (day/night), $14 \mathrm{~h}$ light, and $200 \mu \mathrm{moL} \cdot \mathrm{m}^{-2} \cdot \mathrm{s}^{-1}$ light intensity. After five weeks, tomato plants were transplanted to a polyethylene plastic pot $(170 \mathrm{~mm}$ in diameter, $165 \mathrm{~mm}$ in height) filled with $2 \mathrm{~kg}$ of soil, each pot with 2 plants. The plants were maintained at $28^{\circ} \mathrm{C}$ in a controlled greenhouse for 1.5 months until the end of the experiment.

The soil collected from a continuous cropping cultivation tomato field (Zhucun Village, Zengcheng City, Guangdong,
China) was sandy loam where the amount of bacterial wilt is relatively high; the proportions of sand, silt, and clay particles at $0-20 \mathrm{~cm}$ soil layer were $73 \%, 22 \%$, and $5 \%$, respectively. The contents of soil organic matter, soil-available $\mathrm{N}, \mathrm{P}$, and $\mathrm{K}$, and soil-total $\mathrm{N}, \mathrm{P}$, and $\mathrm{K}$ were $16.30 \mathrm{~g} \mathrm{~kg}^{-1}, 115.47 \mathrm{mg} \mathrm{kg}^{-1}$, $151.10 \mathrm{mg} \mathrm{kg}^{-1}, 82.54 \mathrm{mg} \mathrm{kg}^{-1}, 0.948 \mathrm{~g} \mathrm{~kg}^{-1}, 1.347 \mathrm{~g} \mathrm{~kg}^{-1}$, and $29.2 \mathrm{~g} \mathrm{~kg}^{-1}$, respectively. Soil $\mathrm{pH}$ was 5.89 and soil $\mathrm{C} / \mathrm{N}$ ratio was 9.82 . The soil samples were sieved at $<2 \mathrm{~mm}$ and stored at $4^{\circ} \mathrm{C}$ until analysis to characterize relevant physical and biochemical attributes of the soil. Biochar was amended to soil before transplantation of tomato plants.

2.2. Biochar. Two kinds of biochar (Sanli New Energy Resources Co., Ltd., Shangqiu, Henan, China) were used in this experiment: biochar made from peanut shell $(\mathrm{BC} 1)$ and wheat straw (BC2). Biochar was prepared via pyrolysis in a vertical kiln with a temperature at $500^{\circ} \mathrm{C}$ and a resistance time of about $2 \mathrm{~h}$ in an anaerobic condition (Sanli New Energy Resources Co., Ltd.). The basic properties of the two biochar treatments are shown in Table 1. Scanning electron microscope images are shown in Figure 1.

2.3. Experimental Design. Four treatments were assessed in this experiment: no biochar and no $R$. solanacearum inoculation (CK); R. solanacearum inoculation (Rs); peanut shell biochar (BC1) amendment and $R$. solanacearum inoculation $(\mathrm{BC} 1+\mathrm{Rs})$; and wheat straw biochar (BC2) amendment and $R$. solanacearum inoculation (BC2 + Rs). The experiment was arranged in a completely randomized design with four replications; each replication had one pot with 2 tomato plants. Our preliminary experiment showed that $2 \% \mathrm{w} / \mathrm{w}$ of the two biochar amendments had the best effects in inhibiting bacterial wilt of tomato. Thus, $2 \% \mathrm{w} / \mathrm{w}$ ratio was used in this experiment. $2 \% \mathrm{w} / \mathrm{w}$ ratio of peanut and wheat biochar was used in this experiment. $28 \mathrm{~d}$ after $R$. solanacearum inoculation, when the plants of $R$. solanacearum treatment all died, soil from all treatment groups was collected to determine the amount of $R$. solanacearum in soil, soil microbial population densities (bacteria, fungi, and actinomycetes), and soil microbial activities (soil sucrase, urease, and neutral phosphatase). Biolog EcoPlate experiment was also conducted when the soil was collected.

2.4. R. solanacearum Inoculation. $R$. solanacearum strain biovar 3 (provided by College of Horticulture, South China Agricultural University, Guangzhou 510642, China) was used to inoculate tomato plants. This strain is a highly aggressive species. The isolate was cultured on 2,3,5triphenyltetrazolium chloride (TTC) medium and incubated 


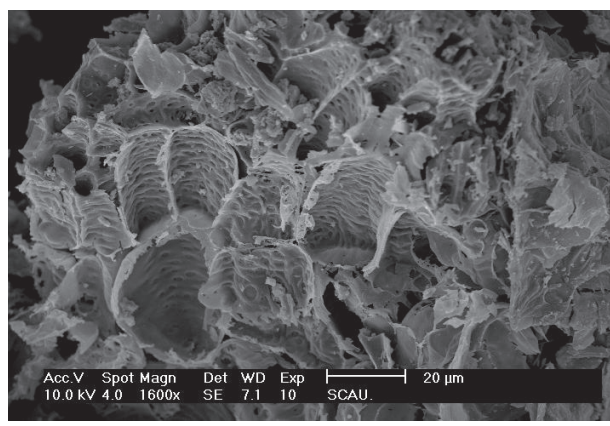

(a)

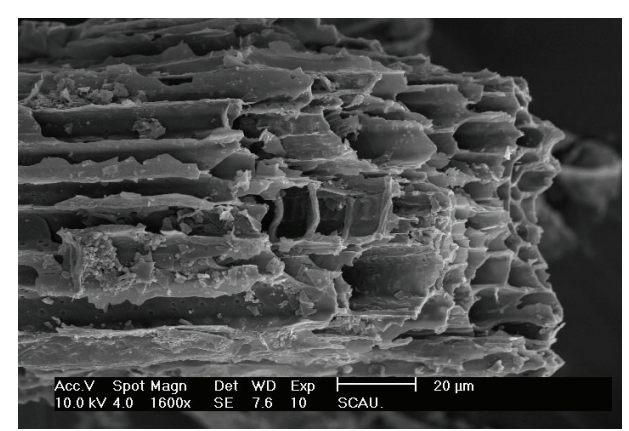

(b)

FIGURE 1: Scanning electron microscope images of two biochar used in this study. (a) Biochar made by peanut shell; (b) biochar made by wheat straw.

at $30^{\circ} \mathrm{C}$ for $48 \mathrm{~h}$; cell density was adjusted to $10^{8} \mathrm{CFU} \cdot \mathrm{mL}^{-1}$ before the isolate was inoculated. As the sixth euphyllia of the tomato plant appeared, the roots of each tomato plant were lightly stabbed and inoculated with $R$. solanacearum by pouring $10 \mathrm{~mL}$ of the bacterial suspension into each pot. CK plants were also stabbed, but the same volume of deionized water was added. After all of the plants of the Rs treatment died, the plants were harvested, and the soil was collected.

2.5. Pathogen Evaluation. Data collection was conducted at an interval of $2 \mathrm{~d}$ after pathogen infection by using a disease score [26] based on 10 plants per treatment. The investigation began when the tomato leaf exhibited symptoms of wilt. The following scoring method was used: 0: no symptom; 1 : one leaf wilted; 3: two or three leaves wilted; 5: all except the top shooting leaves wilted; 7: all leaves wilted; and 9: stems collapsed or plants died.

Disease index was calculated using the following equation: disease index $(\%)=\left[\sum(r \times N r) /(R \times n)\right] \times 100 \%$, where $r$ is the rating value, $N r$ is the number of infected leaves with a rating of $r, R$ is the value of the most serious disease severity, and $n$ is the total number of tested plants [26].

2.6. Determination of the Amount of $R$. solanacearum in Soil. The amount of $R$. solanacearum in soil was determined according to the method described by Wang et al. [27] with minor modification. At $25 \mathrm{~d}$ after pathogen inoculation, $10 \mathrm{~g}$ of fresh soil was collected, added to flasks with $90 \mathrm{~mL}$ of sterile water, and diluted to $10^{-5}$. The soil-suspending liquid was spread with TTC medium (bacterial general medium with $100 \mu \mathrm{L} \cdot \mathrm{mL}^{-1}$ 2,3,5-triphenyltetrazolium chloride) and then incubated for $2 \mathrm{~d}$ at $30^{\circ} \mathrm{C}$ in an incubator (GXZ Intelligent, Jiangnan Instrument Plant). Plate culture count was performed to record the amount of $R$. solanacearum in soil.

2.7. Determination of Soil Microbial Population Densities. The population densities of bacteria, fungi, and actinomycetes were determined using the dilution method described by Martin [28]. The media (Guangdong Huankai Microbial Sci. \& Tech, Co., Ltd., China) for cultivating bacteria, fungi, and actinomycetes were nutrient agar, rose Bengal agar, and gauze's medium number 1 , respectively. Fresh soil (10 g) was added to a flask with $90 \mathrm{~mL}$ of sterile water and shaken in a shaker (TaiCang Experimental Factory \& Suzhou Bing Lab Equipment Co., Ltd., Suzhou, China) for $30 \mathrm{~min}$ at $150 \mathrm{rpm}$. Afterward, $100 \mu \mathrm{L}$ of supernatant fluid from each sample was extracted into a $2 \mathrm{~mL}$ sterile centrifuge tube with $900 \mu \mathrm{L}$ of sterile water. Vortex Genius was used to mix the solution in the centrifuge tube. The solution was diluted to $10^{-5}, 10^{-3}$, and $10^{-5}$ for bacterial, fungal, and actinomycetes analyses, respectively. The dilution was spread in the corresponding medium and then placed in an incubator (GXZ Intelligent, Jiangnan Instrument Plant) at $30^{\circ} \mathrm{C}$. Bacteria, fungi, and actinomycetes were cultured for 2,5 , and $5 \mathrm{~d}$, respectively. After these microorganisms were incubated, the number of colonies was recorded to determine the densities of different microbial populations.

2.8. Determination of Soil Enzyme Activity. Soil urease activity was determined using the method described by Yao and Huang [29]. Air-dried, finely sifted soil (5 g, passed through a $2 \mathrm{~mm}$ sieve) was placed in a $50 \mathrm{~mL}$ conical flask. Approximately $1 \mathrm{~mL}$ of toluene was added to the flask. After $15 \mathrm{~min}, 10 \mathrm{~mL}$ of $10 \%$ urea solution and $20 \mathrm{~mL}$ of citrate buffer ( $\mathrm{pH}$ 6.7) were added. The flasks were immediately shaken and placed in an incubator (GXZ Intelligent; Jiangnan Instrument Plant) at $37 \pm 1^{\circ} \mathrm{C}$ for $24 \mathrm{~h}$. The sample was incubated and filtered using a filter paper. Soil urease activity was colorimetrically determined at $578 \mathrm{~nm}$ with a UV/Vis spectrophotometer (T90 UV/Vis spectrophotometer; PGeneral, Beijing, China) for $1 \mathrm{~h}$.

Considering that soil $\mathrm{pH}$ was mostly neutral in this study, we determined soil neutral phosphatase enzyme activity; soil neutral phosphatase is the main phosphatase enzyme [30]. Neutral phosphatase was determined using a previously described chemical method [27], similar to urease measurement. Soil neutral phosphatase activity was colorimetrically determined at $660 \mathrm{~nm}$ with a UV/Vis spectrophotometer (T90 UV/Vis spectrophotometer; PGeneral, Beijing, China).

Soil sucrase activity was tested according to the method described by Ling and Zhang [31]. In brief, $2 \mathrm{~g}$ of air-dried soil (sieved through $<1 \mathrm{~mm}$ ), $15 \mathrm{~mL}$ of $8 \%$ glucose solution, $5 \mathrm{~mL}$ of $0.2 \mathrm{M}$ phosphate buffer ( $\mathrm{pH} 5.5$ ), and $1 \mathrm{~mL}$ of toluene were added to a $50 \mathrm{~mL}$ conical flask. The solution was incubated 


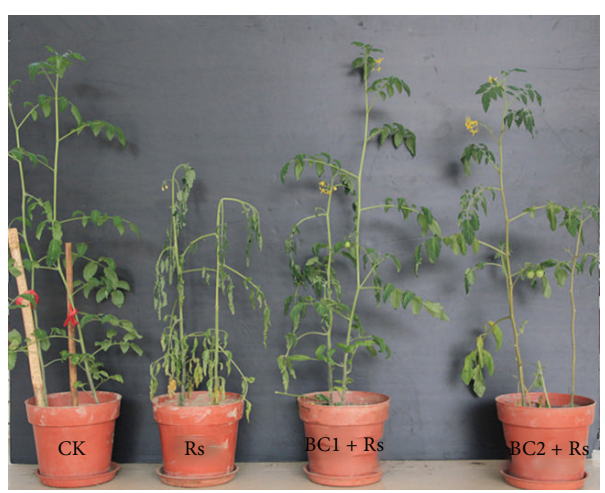

(a)

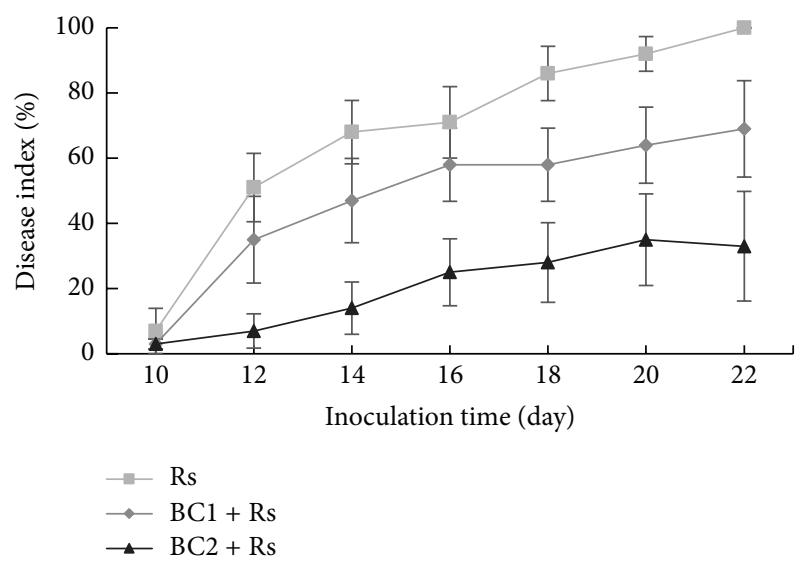

(b)

FIGURE 2: Suppressive effects of biochar amendment on $R$. solanacearum of tomato plant (a) and effects of biochar amendment and $R$. solanacearum inoculation on the disease index (\%) of bacterial wilt in tomato plants (b). CK, no biochar and no R. solanacearum inoculation; Rs, $R$. solanacearum inoculation; $\mathrm{BC} 1+\mathrm{Rs}$, peanut biochar amendment and $R$. solanacearum inoculation; $\mathrm{BC} 2+\mathrm{Rs}$, wheat biochar (BC2) amendment and $R$. solanacearum inoculation.

for $24 \mathrm{~h}$ at $37 \pm 1^{\circ} \mathrm{C}$ and filtered; afterward, $1 \mathrm{~mL}$ of aliquot was transferred to a test tube with $3 \mathrm{~mL}$ of 3,5-dinitrosalicylic acid (DNS) solution. The sample was heated in boiled water for $5 \mathrm{~min}$, cooled in water for $3 \mathrm{~min}$, and colorimetrically quantified at $508 \mathrm{~nm}$ by using a spectrophotometer (T90 $\mathrm{UV} /$ Vis spectrophotometer; PGeneral, Beijing, China).

2.9. Microbial Community Analysis with Biolog EcoPlates. The intensity and the diversity of bacterial metabolism were evaluated using Biolog EcoPlates [32]. Ten grams of fresh soil aliquots was added to $90 \mathrm{~mL}$ of sterile saline solution $(0.85 \% \mathrm{w} / \mathrm{v} \mathrm{NaCl})$ and diluted to $10^{-3}$ with the same solution. Afterward, $150 \mu \mathrm{L}$ of diluted solution was added to each well of Biolog EcoPlate (Biolog, CA) and incubated at $30^{\circ} \mathrm{C}$ for $168 \mathrm{~h}$. Absorbance at $590 \mathrm{~nm}$ was recorded with Biolog MicroStation (Bio Tec Instruments, Inc., CA, USA) at an interval of $24 \mathrm{~h}$; data were analyzed using average well color development (AWCD).

Biolog data obtained after $168 \mathrm{~h}$ of incubation in AWCD were subjected to Shannon diversity $\left(H^{\prime}\right)$ analysis to determine microbial functional diversity. $H^{\prime}$ was calculated using the following equation [33]:

$$
\begin{gathered}
H^{\prime}=-\sum_{i=1}^{31}\left(P_{i} \times \ln P_{i}\right), \\
P_{i}=\frac{\left(C_{i}-R\right)}{\sum_{i=1}^{31}\left(C_{i}-R\right)},
\end{gathered}
$$

where $C_{i}$ is the color production within each well and $R$ is the absorbance value of the plate's control well.

2.10. Soil pH Analysis. As the soil was acidic soil from southern part of China, soil $\mathrm{pH}$ was determined with two different kinds of solutions (1 $\mathrm{M} \mathrm{KCl}$ for $\mathrm{CK}$ and Rs treatments; aqueous solution for $\mathrm{BC} 1$ and $\mathrm{BC} 2$ treatments). The ratio of soil and solution was $1: 2.5$. Briefly, $10 \mathrm{~g}$ aliquots of air-dry soil from the four treatments were each added to $25 \mathrm{~mL}$ solution. The mix solution was shaken for $30 \mathrm{~min}$ at $150 \mathrm{rpm}$ and then stood for $1 \mathrm{~h}$. Subsequently, soil $\mathrm{pH}$ was measured, respectively, by PHS-3C PH Meter (Shanghai REX Instrument Factory, Shanghai, China).

2.11. Statistical Analysis. Data in the figures were expressed as mean \pm standard error of four replicates and analyzed by one-way ANOVA in SPSS17.0 (Statistical Analysis Systems Institute; SPSS Inc., Chicago, IL, USA). Statistical differences among treatments were determined by Duncan's test $(P<$ 0.05). Graphs were constructed using SigmaPlot 12.5 (Systat Software, Inc., San Jose, CA, USA).

\section{Results}

3.1. Effects of Biochar Application on Disease Severity. The symptoms of bacterial wilt in $R$. solanacearum-inoculated treatment were observed at $4 \mathrm{~d}$ postinoculation (dpi). By contrast, these symptoms in biochar-amended treatment were observed only at $10 \mathrm{dpi}$, indicating that biochar amendment delayed pathogen development. Both biochar treatments significantly suppressed disease development and increased disease resistance of tomato plants (Figure 2). Compared with Rs treatment, $\mathrm{BCl}+\mathrm{Rs}$ treatment reduced the disease index of bacterial wilt by $60.00 \%, 30.61 \%, 32.26 \%$, and $30.56 \%$ at $10,14,20$, and $24 \mathrm{dpi}$, respectively. BC2 + Rs treatment reduced the disease index by $60.00 \%, 79.59 \%, 67.74 \%$, and $66.67 \%$, respectively. These results showed that $\mathrm{BC} 2$ was could effectively reduce bacterial wilt to a greater extent than BC1.

3.2. Effects of Biochar Application on the Density of $R$. solanacearum in Soil. Compared with CK treatment, the density of $R$. solanacearum was markedly increased by $80.43 \%$ after pathogen inoculation. However, biochar treatments significantly decreased the density of $R$. solanacearum by 


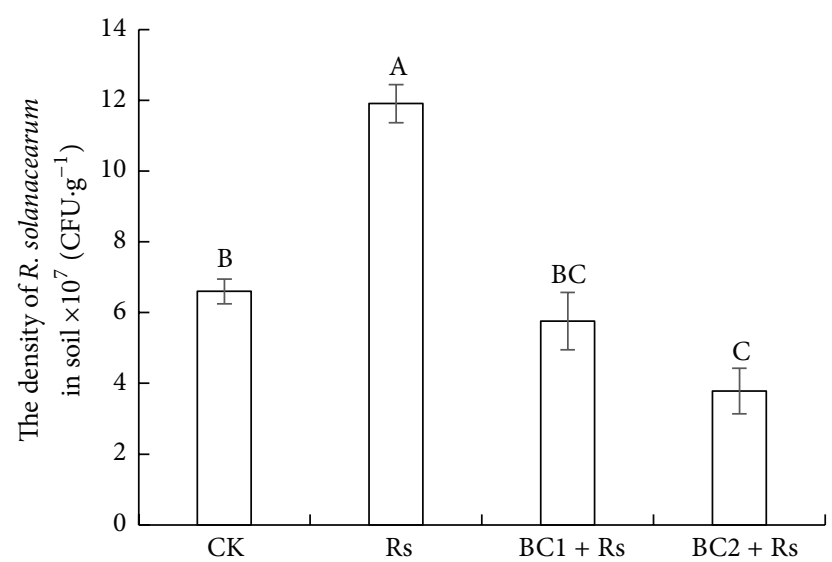

FIgURE 3: Effects of biochar amendment and R. solanacearum inoculation on $R$. solanacearum density in soil. CK, no biochar and no $R$. solanacearum inoculation; Rs, $R$. solanacearum inoculation; $\mathrm{BC} 1$ + Rs, peanut biochar amendment and $R$. solanacearum inoculation; $\mathrm{BC} 2+\mathrm{Rs}$, wheat biochar (BC2) amendment and $R$. solanacearum inoculation. Different letters on the columns denote a significant difference at $P<0.05$ using the DMRT (Duncan's new multiple range tests) method.

51.63\% (BC1) and 68.22\% (BC2) compared with Rs treatment alone (Figure 3).

\subsection{Effects of Biochar Application on Soil Microbial Popu-} lation Densities. Biochar amendment and R. solanacearum inoculation significantly influenced the density of soil microbial population (Figure 4). Compared with CK treatment, $R$. solanacearum inoculation significantly decreased the amounts of soil bacteria and actinomycetes by $57.55 \%$ and $26.45 \%$, respectively. By contrast, $R$. solanacearum inoculation increased the amount of fungi by $272.58 \%$. However, biochar in $\mathrm{BC} 1+\mathrm{Rs}$ and $\mathrm{BC} 2+$ Rs treatments significantly increased soil bacteria by $57.39 \%$ and $96.42 \%$ and soil actinomycetes by $42.47 \%$ and $63.33 \%$ and reduced soil fungi by $65.87 \%$ and $29.73 \%$, respectively.

$R$. solanacearum inoculation significantly increased soil fungi/actinomycetes ratio and fungi/bacteria ratio by $418.44 \%$ and $735.14 \%$, respectively. However, these ratios were decreased by $76.81 \%$ and $78.57 \%$ in $\mathrm{BC} 1+\mathrm{Rs}$ and by $56.76 \%$ and $63.34 \%$ in $\mathrm{BC} 2+$ Rs treatments, respectively, compared with Rs treatment (Figure 5).

3.4. Effects of Biochar Application on Soil Enzyme Activity. Soil neutral phosphatase and urease activities were significantly affected by $R$. solanacearum inoculation (Figure 6). Compared with $\mathrm{CK}$ treatment, $R$. solanacearum infection reduced soil neutral phosphatase activity by $83.39 \%$ and soil urease activity by $4.52 \%$. Biochar amendments increased soil enzyme activities. In particular, $\mathrm{BC} 1+\mathrm{Rs}$ and $\mathrm{BC} 2+\mathrm{Rs}$ treatments increased soil neutral phosphatase by $458.70 \%$ and $329.15 \%$, respectively (Figure 6(a)); likewise, these treatments increased soil urease activity by $15.36 \%$ and $14.08 \%$, respectively (Figure 6(b)). R. solanacearum inoculation did not significantly affect soil sucrase activity; however, biochar amendments decreased soil sucrase activity (Figure 6(c)) by $29.94 \%(\mathrm{BC} 1+\mathrm{Rs})$ and $27.97 \%(\mathrm{BC} 2+\mathrm{Rs})$.

3.5. Effects of Biochar Application on Physiological Profiles at a Microbial Community Level. Biolog assay was originally developed to identify microbial isolates based on substrate utilization profiles. This assay is commonly performed to obtain substrate utilization profiles at a community level [32]. Color intensity was determined by calculating the AWCD of each plate. The AWCD values of different treatments at different stages are shown in Figure 7. Biochar treatments yielded higher AWCD than nonbiochar treatments, especially after $72 \mathrm{~h}$; this result indicated that the tested metabolic capabilities of biochar treatments were higher than those of nonbiochar treatments. The physiological profiles of biochar treatments significantly differed at specific representative stages $(96,144$, and $168 \mathrm{~h}$ after incubation).

We selected $144 \mathrm{~h}$ after cultivation as a specific time to identify differences in AWCD value of each treatment because $144 \mathrm{~h}$ is the logarithmic period of soil microbes. The results showed that Rs treatment decreased the AWCD value by $3.29 \%$ compared with CK treatment; by contrast, biochar treatments significantly increased AWCD by $15.21 \%(\mathrm{BC} 1+$ Rs treatment) and $15.53 \%$ (BC2 + Rs treatment), compared with Rs treatment.

3.6. Effects of Biochar Application on Soil pH. Soil pH was significantly increased after biochar amendment regardless of pathogen inoculation (Figure 8). Pathogen inoculation decreased soil $\mathrm{pH}$ by $3.16 \%$ compared with $\mathrm{CK}$ treatments. Biochar amendment treatments increased soil $\mathrm{pH}$ by $27.53 \%$ (BC1) and $22.67 \%$ (BC2) compared with Rs treatment, respectively. The soil was increased to around neutral $\mathrm{pH}$ by biochar amendment (Figure 8).

\section{Discussion}

The beneficial role of biochar inducing plant diseases resistance has been investigated in several foliar and soilborne pathosystems $[14,15,34]$. In the present study, $2 \%$ w/w peanut and wheat biochar amendment delayed $R$. solanacearum development, significantly reduced the severity of disease incidence, and increased tomato plant resistance. The density of $R$. solanacearum in soil was also significantly decreased by biochar application. And also due to biochar amendment, soil $\mathrm{pH}$ got back to the neutral level which is good for bacteria growth.

The soil microbial population structure is critical to soil function and ecosystem services, which affect soil structure and stability, nutrient cycling, aeration, water use efficiency, disease resistance, and $C$ storage capacity [35]. In previous reports, the increase in bacterial densities is associated with the enhanced resistance of amended soils against southern blight of processing tomatoes, Phytophthora root rot of alfalfa, and potato scab $[36,37]$. Beneficial microbiota can compete with pathogens for space and nutrients or produce microbial agents, thereby improving plant health [38]. Our results showed that the density of soil bacteria and actinomycetes 


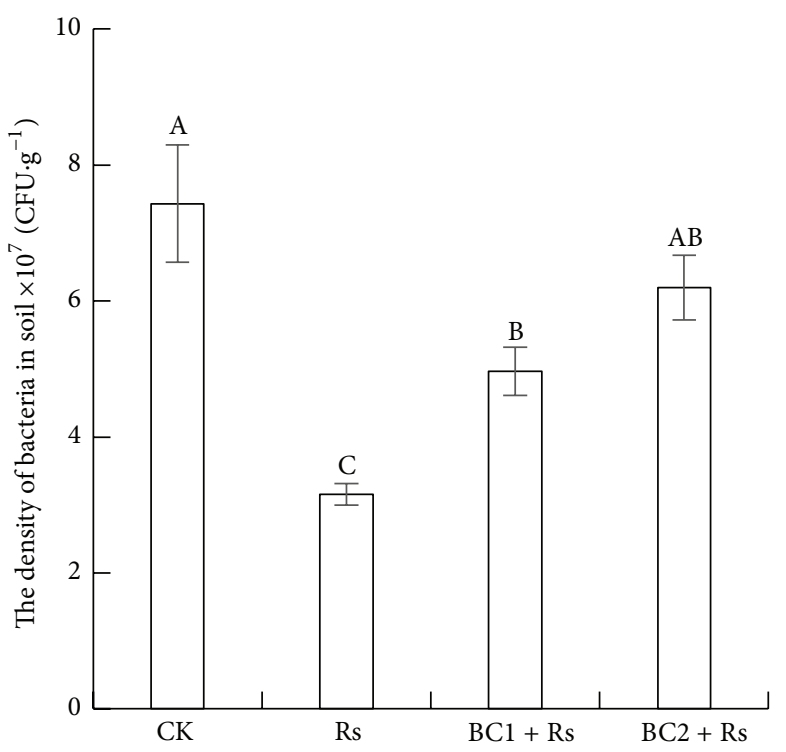

(a)

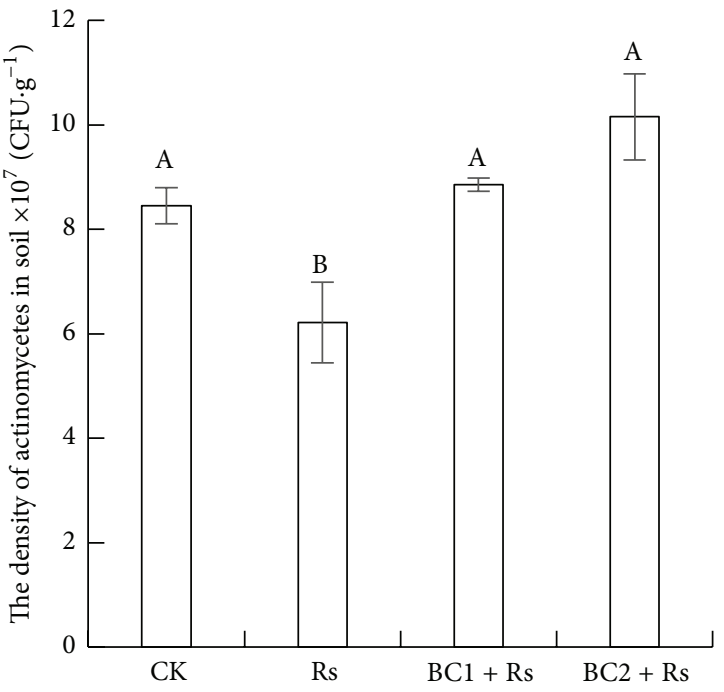

(b)

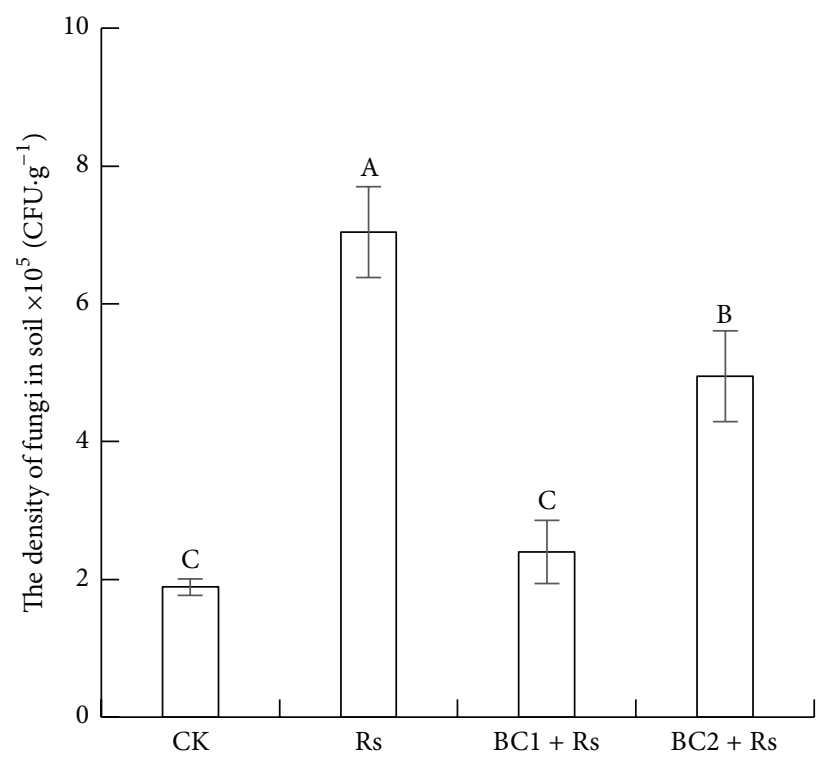

(c)

FIGURE 4: Effects of biochar amendment and R. solanacearum on the amount of soil bacteria (a), actinomycetes (b), and fungi (c). CK, no biochar and no $R$. solanacearum inoculation; Rs, $R$. solanacearum inoculation; BC1 + Rs, peanut biochar amendment and $R$. solanacearum inoculation; $\mathrm{BC} 2+\mathrm{Rs}$, wheat biochar (BC2) amendment and $R$. solanacearum inoculation. Different letters on the columns denote a significant difference at $P<0.05$ using the DMRT (Duncan's new multiple range tests) method.

was significantly decreased after $R$. solanacearum was inoculated; by contrast, the amount of soil fungi increased. Thus, soil was converted from "bacterial type" to "fungal type," and this result is similar to that of Larkin [23]. Interestingly, biochar addition to $R$. solanacearum-infected soil could increase the amount of soil bacteria and actinomycetes; conversely, biochar addition could decrease the amount of soil fungi, soil fungi/bacteria ratio, and fungi/actinomycetes ratio to reverse the change in soil microorganism composition that resulted from pathogen infection. And this finding is similar to that in a previous study in which silicon supply resulted in the change of soil microbial components under pathogen inoculation [27].

Our results also showed that higher metabolic capabilities were found in the two biochar amendment treatments at 96 and $144 \mathrm{~h}$ (two sensitive stages during cultivation), indicating that biochar addition resulted in high substrate utilization capability of microorganism. What is more, a good relationship is observed between soil fertility and soil microorganisms. In plants, soil microbes interact to mediate and influence various exchanges that contribute to plant growth and productivity [21]. The extent of these effects 


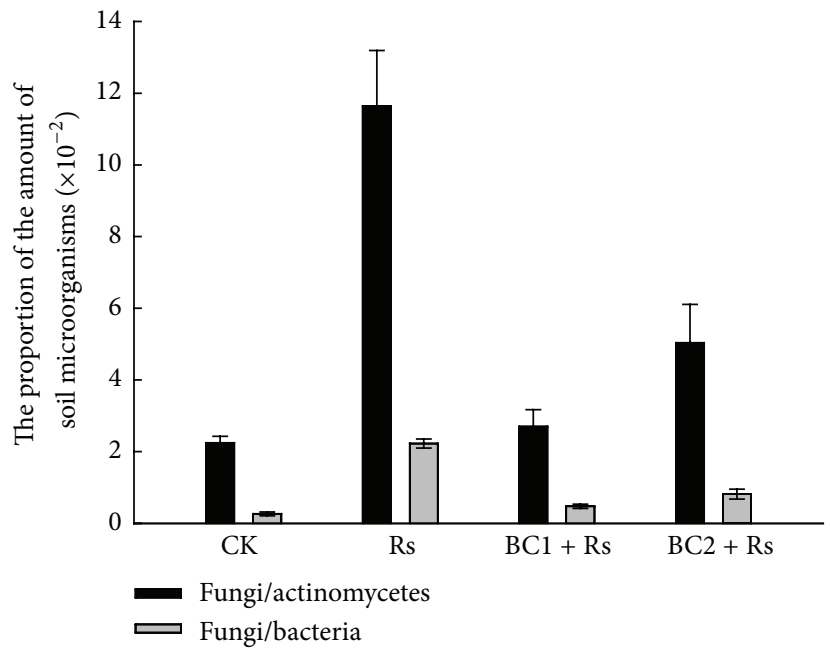

FIGURE 5: Effects of biochar amendment and $R$. solanacearum on the ratio of soil microorganism: fungi/actinomycetes and fungi/bacteria. CK, no biochar and no $R$. solanacearum inoculation; Rs, $R$. solanacearum inoculation; $\mathrm{BC} 1+$ Rs, peanut biochar amendment and $R$. solanacearum inoculation; $\mathrm{BC} 2+\mathrm{Rs}$, wheat biochar (BC2) amendment and R. solanacearum inoculation.

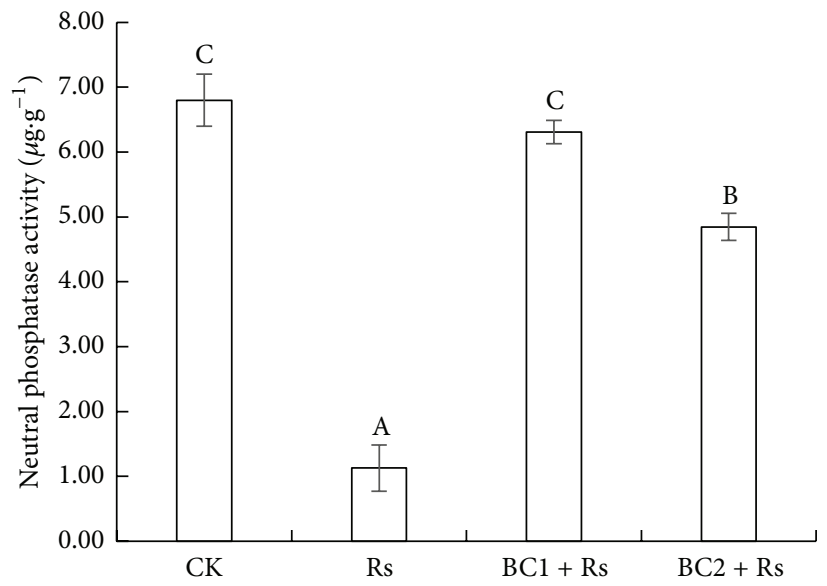

(a)

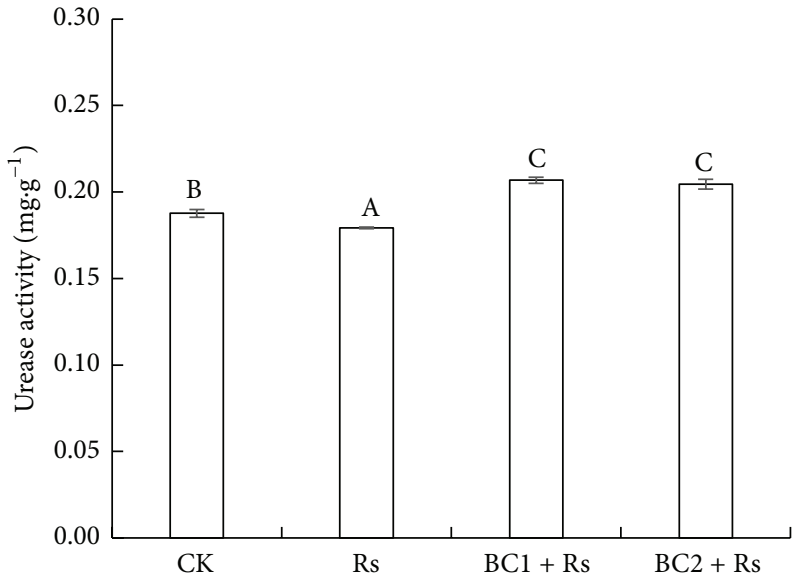

(b)

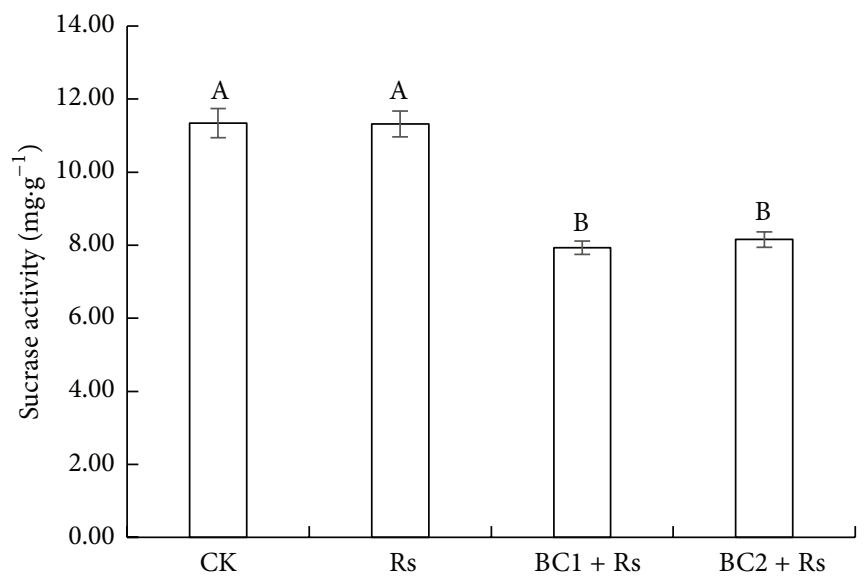

(c)

FIGURE 6: Effects of biochar amendment and R. solanacearum inoculation on the activity of soil neutral phosphatase (a), urease (b), and sucrase (c). CK, no biochar and no R. solanacearum inoculation; Rs, $R$. solanacearum inoculation; $\mathrm{BC} 1+\mathrm{Rs}$, peanut biochar amendment and $R$. solanacearum inoculation; $\mathrm{BC} 2+\mathrm{Rs}$, wheat biochar $(\mathrm{BC} 2)$ amendment and $R$. solanacearum inoculation. Different letters on the columns denote a significant difference at $P<0.05$ using the DMRT (Duncan's new multiple range tests) method. 


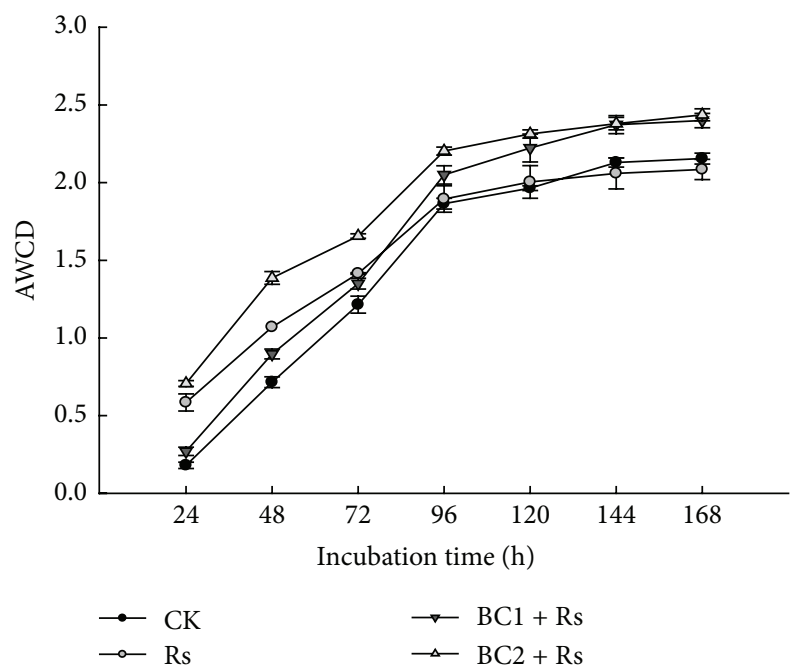

FIGURE 7: Effects of biochar amendment and R. solanacearum on soil microorganism community-level substrate utilization profiles. CK, no biochar and no $R$. solanacearum inoculation; Rs, $R$. solanacearum inoculation; $\mathrm{BCl}+\mathrm{Rs}$, peanut biochar amendment and $R$. solanacearum inoculation; BC2 + Rs, wheat biochar (BC2) amendment and $R$. solanacearum inoculation.

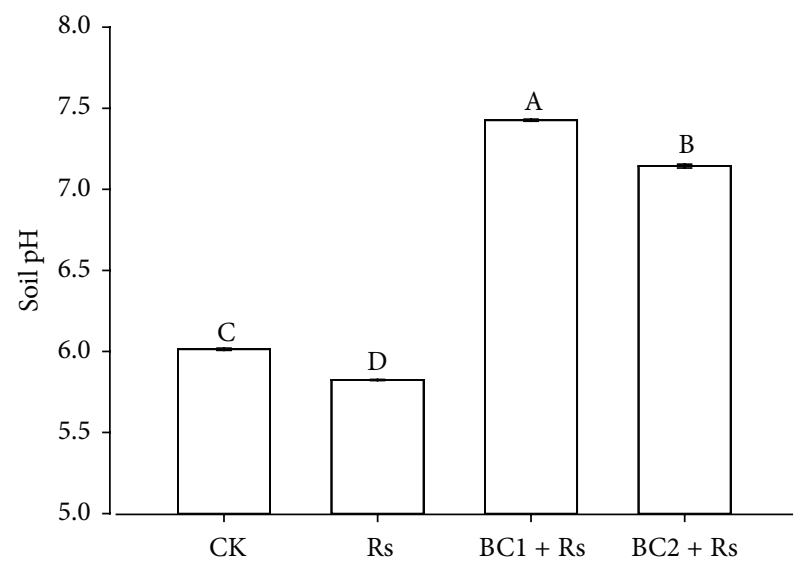

FIGURE 8: Effects of treatment on soil $\mathrm{pH}$. CK, no biochar and no $R$. solanacearum inoculation; Rs, $R$. solanacearum inoculation; $\mathrm{BC1}$ + Rs, peanut biochar amendment and $R$. solanacearum inoculation; $\mathrm{BC} 2+\mathrm{Rs}$, wheat biochar (BC2) amendment and $R$. solanacearum inoculation. Different letters on the columns denote a significant difference at $P<0.05$ using the DMRT (Duncan's new multiple range tests) method.

likely depends on biochar production conditions and feedstock, which control macrostructures and microstructures of biochar particles [12]. Brussaard et al. suggested that organic amendments are possibly among the most important strategies of soil biodiversity management [39].

Soil enzymes are direct mediators of biological catabolism of soil organic and mineral components. As an integral part of nutrient cycling in soil, soil-specific enzyme activities, including dehydrogenase and phosphatase activities, can be used to estimate soil microbial activity and evaluate soil health [40]. Soil microbial activity is implicated in quantifying soil function, such as $\mathrm{C}$ and $\mathrm{N}$ cycles and organic matter decomposition [41, 42]. Some enzymes (e.g., hydrolase and glucosidase) facilitate the breakdown of organic matter; other enzymes (e.g., amidase, urease, phosphatase, and sulfatase) are involved in nutrient mineralization. Urease, phosphatase, and arylsulphatase are important in the mineralization of nitrogen, phosphorous, and sulfur compounds [40]. Moreover, soil enzymes may exhibit a strong relationship with disease suppression. Some enzymes (e.g., chitinases and/or glucanases) may reinforce plant resistance to pathogens by breaking down polysaccharides, chitin, and $\beta$-glucans responsible for the rigidity of fungal cell walls, thereby destroying cell wall integrity [43]. Baek et al. found that chitinase enzyme activity is positively correlated with suppression ability of Rhizoctonia solani-incited cotton seedling disease [44]. Woo et al. reported that biocontrol activity against $B$. cinerea on bean leaves was reduced when chitinase activity is disrupted [45]. In this study, R. solanacearum infection significantly reduced soil neutral phosphatase and urease activities; by contrast, biochar amendment increased enzyme activities and maintained a relatively higher soil microbial activity. The activity of microorganisms related to soil neutral phosphatase and urease was enhanced.

In conclusion, our study indicates that both peanut and wheat biochar applications significantly reduced the severity of bacterial wilt caused by $R$. solanacearum. Biochar amendment could increase the population densities of soil bacteria and actinomycetes, modify soil fungi/bacteria and fungi/actinomycetes ratio, increase soil microbial activity, and suppress $R$. solanacearum distribution to establish a healthy soil environment. The pathogen resistance of tomato after biochar amendment is closely related to the changes in soil microbial activity and community structure. Further studies could be conducted by molecular microbiology and sequencing technologies to identify specific soil microbial group or species with antagonistic roles against $R$. solanacearum.

\section{Abbreviations}

TTC: 2,3,5-Triphenyltetrazolium chloride Rs: $\quad$ R. solanacearum.

\section{Competing Interests}

The authors declare that they have no competing interests.

\section{Acknowledgments}

This study was financially supported by grants from the National Key Basic Research Funds of China (2011CB100400), the National Natural Science Foundation of China (31370456), Doctoral Foundation of the Ministry of Education of China (20124404110007), and the Natural Science Foundation of Guangdong Province (S2012010010331). They would like to thank Professor Shiming Luo at South China Agricultural University, China, 
for reviewing this paper and giving useful suggestions and comments.

\section{References}

[1] E. Yabuuchi, Y. Kosako, I. Yano, H. Hotta, and Y. Nishiuchi, "Transfer of two Burkholderia and an Alcaligenes species to Ralstonia gen. nov.: proposal of Ralstonia pickettii (Ralston, Palleroni and Doudoroff 1973) comb. nov., Ralstonia solanacearum (Smith 1896) comb. nov. and Ralstonia eutropha (Davis 1969) comb. nov.," Microbiology and Immunology, vol. 39, no. 11, pp. 897-904, 1995.

[2] J. Muthoni, H. Shimelis, and R. Melis, "Management of bacterial wilt (Rhalstonia solanacearum Yabuuchi et al., 1995) of potatoes: opportunity for host resistance in Kenya," The Journal of Agricultural Science, vol. 4, no. 9, pp. 64-78, 2012.

[3] R. Kubota, B. G. Vine, A. M. Alvarez, and D. M. Jenkins, "Detection of Ralstonia solanacearum by loop-mediated isothermal amplification," Phytopathology, vol. 98, no. 9, pp. 1045-1051, 2008.

[4] N. A. S. Messiha, A. D. Van Diepeningen, M. Wenneker et al., "Biological Soil Disinfestation (BSD), a new control method for potato brown rot, caused by Ralstonia solanacearum race 3 biovar 2," European Journal of Plant Pathology, vol. 117, no. 4, pp. 403-415, 2007.

[5] A. R. Zimmerman, "Abiotic and microbial oxidation of laboratory-produced black carbon (biochar)," Environmental Science and Technology, vol. 44, no. 4, pp. 1295-1301, 2010.

[6] K. Y. Chan, L. Van Zwieten, I. Meszaros, A. Downie, and S. Joseph, "Agronomic values of greenwaste biochar as a soil amendment," Soil Research, vol. 45, no. 8, pp. 629-634, 2007.

[7] E. R. Graber, Y. M. Harel, M. Kolton et al., "Biochar impact on development and productivity of pepper and tomato grown in fertigated soilless media," Plant and Soil, vol. 337, no. 1, pp. 481496, 2010.

[8] S. Jeffery, F. G. A. Verheijen, M. van der Velde, and A. C. Bastos, "A quantitative review of the effects of biochar application to soils on crop productivity using meta-analysis," Agriculture, Ecosystems and Environment, vol. 144, no. 1, pp. 175-187, 2011.

[9] Y. Elad, E. Cytryn, Y. M. Harel, B. Lew, and E. R. Graber, "The biochar effect: plant resistance to biotic stresses," Phytopathologia Mediterranea, vol. 50, no. 3, pp. 335-349, 2011.

[10] J. M. Novak, W. J. Busscher, D. L. Laird, M. Ahmedna, D. W. Watts, and M. A. S. Niandou, "Impact of biochar amendment on fertility of a southeastern coastal plain soil," Soil Science, vol. 174, no. 2, pp. 105-112, 2009.

[11] C. Steiner, W. G. Teixeira, J. Lehmann et al., "Long term effects of manure, charcoal and mineral fertilization on crop production and fertility on a highly weathered Central Amazonian upland soil," Plant and Soil, vol. 291, no. 1-2, pp. 275-290, 2007.

[12] J. Lehmann, S. Joseph, F. Casanoves et al., Biochar for Environmental Management: Science and Technology, 2010.

[13] D. Wardle, O. Zackrisson, and M. Nilsson, "The charcoal effect in Boreal forests: mechanisms and ecological consequences," Oecologia, vol. 115, no. 3, pp. 419-426, 1998.

[14] Y. Elad, D. R. David, Y. M. Harel et al., "Induction of systemic resistance in plants by biochar, a soil-applied carbon sequestering agent," Phytopathology, vol. 100, no. 9, pp. 913-921, 2010.

[15] Y. M. Harel, Y. Elad, D. Rav-David et al., "Biochar mediates systemic response of strawberry to foliar fungal pathogens," Plant and Soil, vol. 357, no. 1, pp. 245-257, 2012.
[16] A. K. Jaiswal, Y. Elad, E. R. Graber, and O. Frenkel, "Rhizoctonia solani suppression and plant growth promotion in cucumber as affected by biochar pyrolysis temperature, feedstock and concentration," Soil Biology and Biochemistry, vol. 69, pp. 110-118, 2014.

[17] M. Nerome, K. Toyota, T. Islam et al., "Suppression of bacterial wilt of tomato by incorporation of municipal biowaste charcoal into soil," Soil Microorganisms, vol. 59, pp. 9-14, 2005.

[18] H. A. Hoitink and P. C. Fahy, "Basis for the control of soilborne plant pathogens with composts," Annual Review of Phytopathology, vol. 24, no. 1, pp. 93-114, 1986.

[19] J. Lehmann, M. C. Rillig, J. Thies, C. A. Masiello, W. C. Hockaday, and D. Crowley, "Biochar effects on soil biota-a review," Soil Biology and Biochemistry, vol. 43, no. 9, pp. 18121836, 2011.

[20] R. Noble and E. Coventry, "Suppression of soil-borne plant diseases with composts: a review," Biocontrol Science and Technology, vol. 15, no. 1, pp. 3-20, 2005.

[21] J. M. Chaparro, A. M. Sheflin, D. K. Manter, and J. M. Vivanco, "Manipulating the soil microbiome to increase soil health and plant fertility," Biology and Fertility of Soils, vol. 48, no. 5, pp. 489-499, 2012.

[22] C. Pankhurst, B. Hawke, H. McDonald et al., "Evaluation of soil biological properties as potential bioindicators of soil health," Australian Journal of Experimental Agriculture, vol. 35, no. 7, pp. 1015-1028, 1995.

[23] R. P. Larkin, "Characterization of soil microbial communities under different potato cropping systems by microbial population dynamics, substrate utilization, and fatty acid profiles," Soil Biology and Biochemistry, vol. 35, no. 11, pp. 1451-1466, 2003.

[24] M. C. C. Leon, A. Stone, and R. P. Dick, "Organic soil amendments: impacts on snap bean common root rot (Aphanomyes euteiches) and soil quality," Applied Soil Ecology, vol. 31, no. 3, pp. 199-210, 2006.

[25] C. N. Kelly, F. C. Calderón, V. Acosta-Martínez et al., "Switchgrass biochar effects on plant biomass and microbial dynamics in two soils from different regions," Pedosphere, vol. 25, no. 3, pp. 329-342, 2015.

[26] Z. Fang, Research Methods of Plant Pathology, China Agriculture Press, Beijing, China, 1998.

[27] L. Wang, K. Cai, Y. Chen, and G. Wang, "Silicon-mediated tomato resistance against Ralstonia solanacearum is associated with modification of soil microbial community structure and activity," Biological Trace Element Research, vol. 152, no. 2, pp. 275-283, 2013.

[28] J. P. Martin, "Use of acid, rose bengal, and streptomycin in the plate method for estimating soil fungi," Soil Science, vol. 69, no. 3, pp. 215-232, 1950.

[29] H. Yao and C. Huang, Soil Microbial Ecology and Its Experimental Technique, Science Press, Beijing, China, 2006.

[30] F. Eivazi and M. A. Tabatabai, "Phosphatases in soils," Soil Biology and Biochemistry, vol. 9, no. 3, pp. 167-172, 1977.

[31] L. Ling and W.-X. Zhang, "Sequestration of arsenate in zerovalent iron nanoparticles: visualization of intraparticle reactions at angstrom resolution," Environmental Science \& Technology Letters, vol. 1, no. 7, pp. 305-309, 2014.

[32] J. L. Garland and A. L. Mills, "Classification and characterization of heterotrophic microbial communities on the basis of patterns of community-level sole-carbon-source utilization," Applied and Environmental Microbiology, vol. 57, no. 8, pp. 23512359, 1991. 
[33] H. Zheng, Z. Y. Ouyang, X. K. Wang, Z. G. Fang, T. Q. Zhao, and H. Miao, "Effects of regenerating forest cover on soil microbial communities: a case study in hilly red soil region, Southern China," Forest Ecology and Management, vol. 217, no. 2-3, pp. 244-254, 2005.

[34] W. H. Elmer and J. J. Pignatello, "Effect of biochar amendments on mycorrhizal associations and Fusarium crown and root rot of asparagus in replant soils," Plant Disease, vol. 95, no. 8, pp. 960-966, 2011.

[35] L. Brussaard, V. M. Behan-Pelletier, D. E. Bignell et al., "Biodiversity and ecosystem functioning in soil," AMBIO: A Journal of the Human Environment, vol. 26, no. 8, pp. 563-570, 1997.

[36] L. R. Bulluck III and J. B. Ristaino, "Effect of synthetic and organic soil fertility amendments on southern blight, soil microbial communities, and yield of processing tomatoes," Phytopathology, vol. 92, no. 2, pp. 181-189, 2002.

[37] B. E. Wiggins and L. L. Kinkel, "Green manures and crop sequences influence alfalfa root rot and pathogen inhibitory activity among soil-borne streptomycetes," Plant and Soil, vol. 268, no. 1, pp. 271-283, 2005.

[38] S. E. Lindow and J. H. J. Leveau, "Phyllosphere microbiology," Current Opinion in Biotechnology, vol. 13, no. 3, pp. 238-243, 2002.

[39] L. Brussaard, P. C. De Ruiter, and G. G. Brown, "Soil biodiversity for agricultural sustainability," Agriculture, Ecosystems \& Environment, vol. 121, no. 3, pp. 233-244, 2007.

[40] L. Gianfreda, M. A. Rao, A. Piotrowska, G. Palumbo, and C. Colombo, "Soil enzyme activities as affected by anthropogenic alterations: intensive agricultural practices and organic pollution," Science of the Total Environment, vol. 341, no. 1-3, pp. 265279, 2005.

[41] J. H. J. R. Makoi and P. A. Ndakidemi, "Selected soil enzymes: examples of their potential roles in the ecosystem," African Journal of Biotechnology, vol. 7, no. 3, pp. 181-191, 2008.

[42] R. Pavel, J. Doyle, and Y. Steinberger, "Seasonal patterns of cellulase concentration in desert soil," Soil Biology \& Biochemistry, vol. 36, no. 3, pp. 549-554, 2004.

[43] C. R. Howell, "Mechanisms employed by Trichoderma species in the biological control of plant diseases: the history and evolution of current concepts," Plant Disease, vol. 87, no. 1, pp. 4-10, 2003.

[44] J.-M. Baek, C. R. Howell, and C. M. Kenerley, "The role of an extracellular chitinase from Trichoderma virens Gv29-8 in the biocontrol of Rhizoctonia solani," Current Genetics, vol. 35, no. 1, pp. 41-50, 1999.

[45] S. L. Woo, B. Donzelli, F. Scala et al., "Disruption of the ech42 (Endochitinase-Encoding) gene affects biocontrol activity in Trichoderma harzianum P1," Molecular Plant-Microbe Interactions, vol. 12, no. 5, pp. 419-429, 2007. 


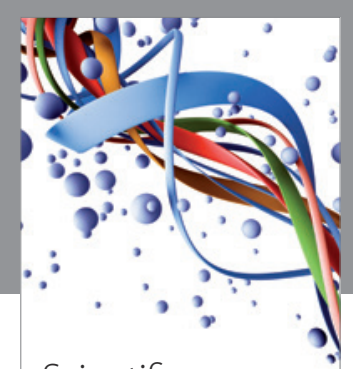

Scientifica
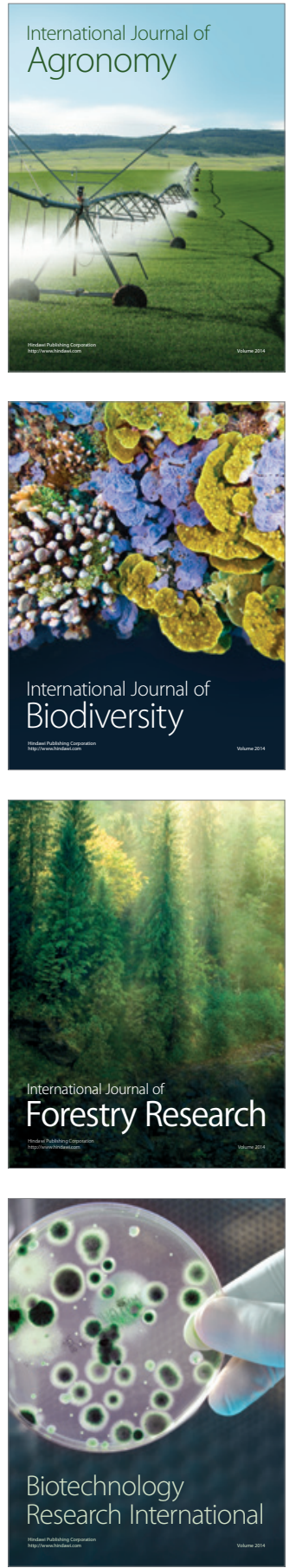
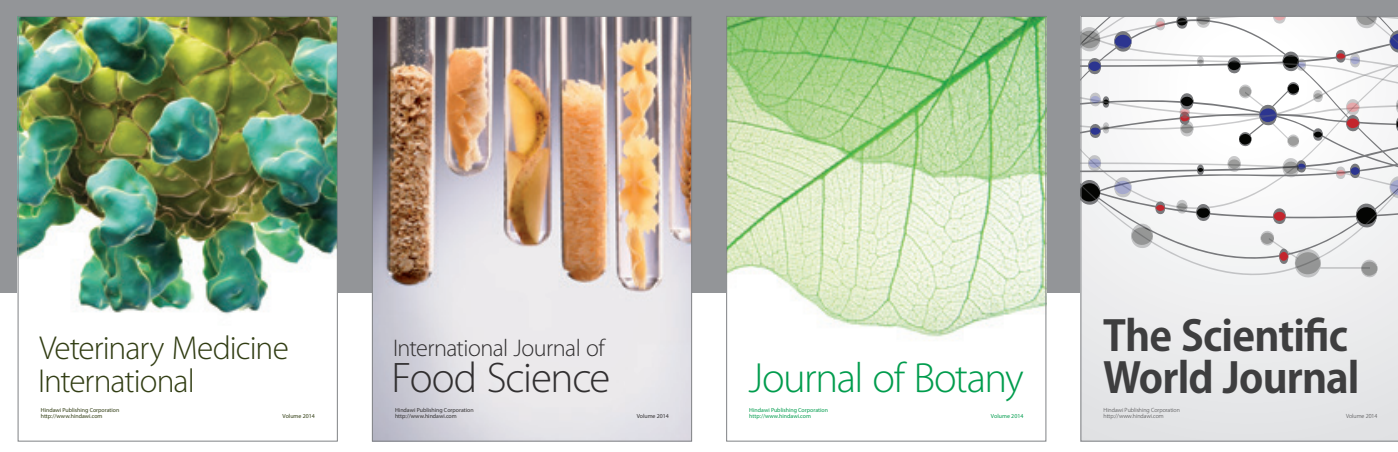

The Scientific

\section{World Journal}

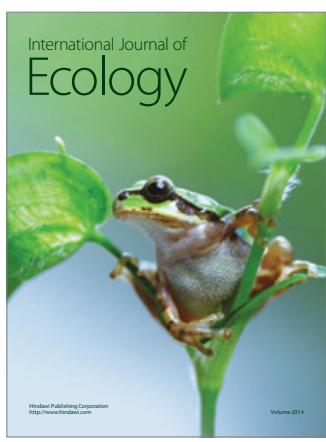

\section{Hindawi}

Submit your manuscripts at

http://www.hindawi.com
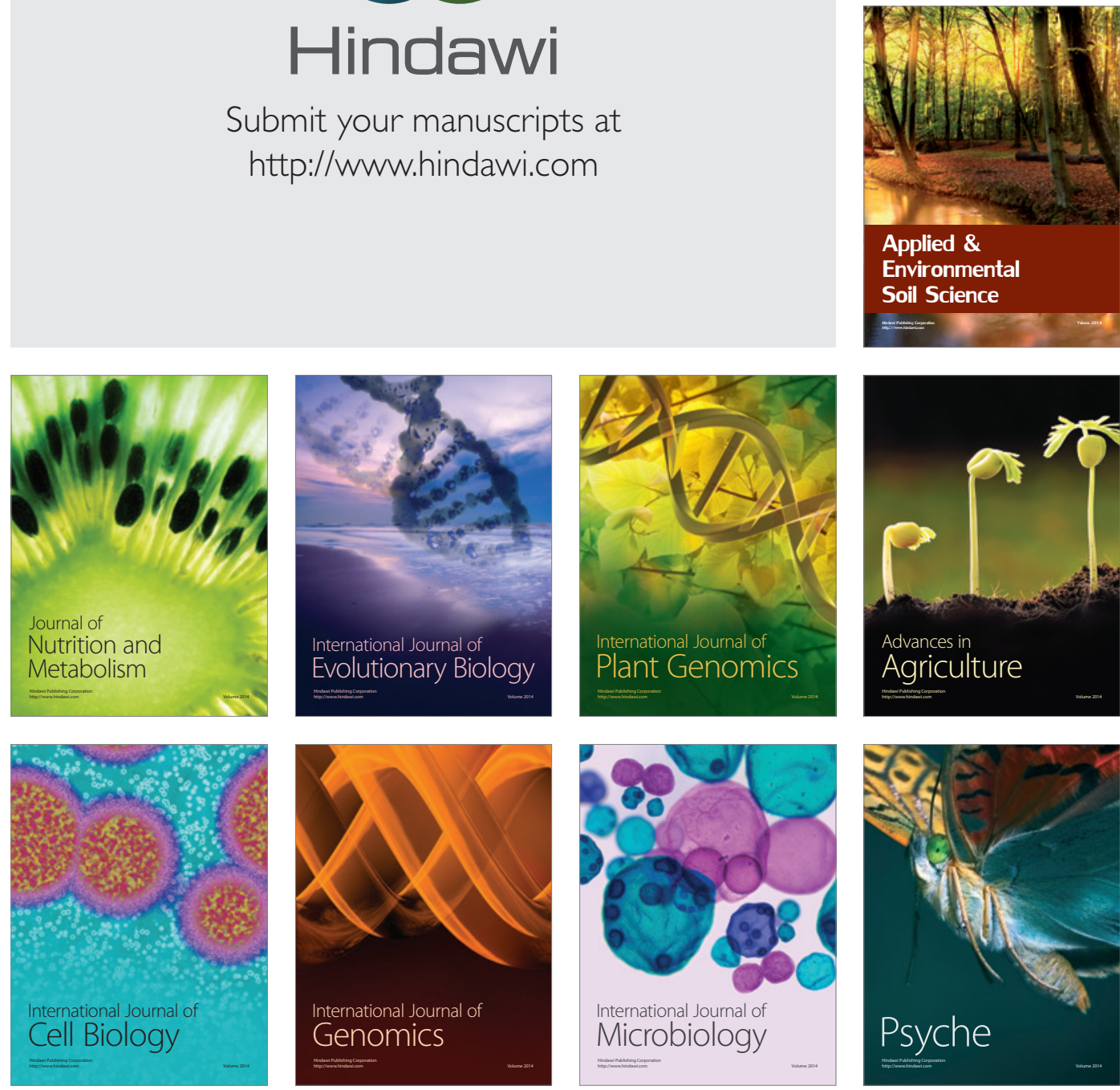
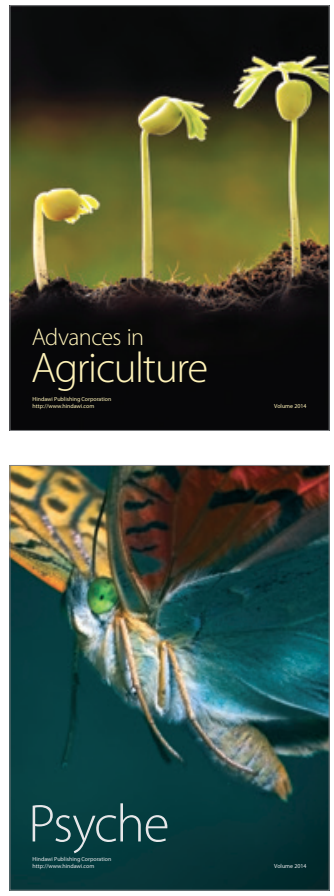